\title{
Renal Denervation: Results of a Single-Center Cohort Study
}

\section{Renale Denervation: Ergebnisse einer Single-Center Kohorten- studie}

Authors

Affiliations
J. A. Luetkens ${ }^{1}$, K. Wilhelm² , R. Düsing ${ }^{3}$, R. P. Woitas ${ }^{4}$, D. Thomas ${ }^{1}$, F. Hundt ${ }^{4}$, J. Doerner ${ }^{1}$, H. H. Schild ${ }^{1}$, C. P. Nähle

Department of Radiology, University of Bonn, Bonn

Department of Radiology, Johanniter Hospital, Bonn

Hypertension Center, Bonn

${ }^{4}$ Department of Internal Medicine I, University of Bonn, Bonn
Key words

- renal arteries

- ablation procedures

- hypertension received 12.5.2014 accepted 25.7.2014

Bibliography

DOI http://dx.doi.org/ 10.1055/s-0034-1385125

Published online: 4.9.2014

Fortschr Röntgenstr 2015; 187 :

36-41 @ Georg Thieme Verlag

KG Stuttgart · New York .

ISSN 1438-9029

\section{Correspondence \\ PD Dr. Claas P. Nähle}

Department of Radiology,

University of Bonn

Sigmund-Freud-Str. 25

53127 Bonn

Germany

Tel.: ++ 49/228/28715963

Fax: $++49 / 228 / 28715960$

cp@naehle.net

\section{Abstract \\ $\nabla$}

Purpose: To investigate the effect of renal denervation on office-based and 24-h ambulatory blood pressure measurements (ABPM) in a highly selective patient population with drug-resistant hypertension.

Materials and Methods: Patients with drug resistant hypertension eligible for renal denervation were included in the study population. Office blood pressure and ABPM were assessed prior to and after renal denervation. To detect procedure related renal or renal artery damage, magnetic resonance imaging (MRI) and angiography (MRA) were performed pre-interventional, one day post-interventional, and one month after renal denervation.

Results: Mean follow-up time between renal denervation and blood pressure re-assessment was $9.5 \pm 3.9$ months. Between August 2011 and March 2013, 17 patients prospectively underwent renal denervation. Pre-interventional mean office blood pressure and ABPM were $177.3 \pm 20.3 / 103.8 \pm 20.4 \mathrm{mmHg}$ and $155.2 \pm 20.5 / 93.7 \pm 14.5 \mathrm{mmHg}$, respectively. Post-interventional, office blood pressure was significantly reduced to 144.7 $\pm 14.9 / 89.5 \pm 12.1(\mathrm{p}<0.05)$. ABPM values remained unchanged $(147.9 \pm 20.3 / 90.3 \pm 15.6$, $p>0.05$ ). The number of prescribed antihypertensive drugs was unchanged after renal denervation ( $4.7 \pm 2.0$ vs. $4.2 \pm 1.2, \mathrm{p}=0.18$ ). No renovascular complications were detected in follow-up MRI.

Conclusion: After renal denervation, no significant decrease in ABPM was observed. These results may indicate a limited impact of renal denervation for drug resistant hypertension.
Key Points:

- Renal denervation showed no significant effects on 24-h ambulatory blood pressure measurements.

- A significant decrease in office blood pressure measurements may be explained by a potential detection bias.

- Renal artery alterations were not observed on follow-up MRI scans.

Citation Format:

- Luetkens J. A., Wilhelm K., Düsing R. etal. Renal Denervation: Results of a Single-Center Cohort Study. Fortschr Röntgenstr 2015; 187: 36-41

\section{Zusammenfassung \\ $\nabla$}

Ziel: Erfassung der Blutdruckveränderung nach renaler Denervation in einem hochselektiven Patientenkollektiv mit therapierefraktärer Hypertonie mittels Praxis- und 24-Stunden-Blutdruckmessung.

Material und Methoden: Zwischen August 2011 und März 2013 wurde bei 17 Patienten mit therapierefraktärer Hypertonie eine renale Denervation durchgeführt. Prä- und postinterventionell wurde der Blutdruck mittels Praxisblutdruckmessung und 24-Stundenmessung bestimmt. Zur Detektion von interventionsassoziierten Veränderungen wurden MRT-Untersuchungen der Nieren und Nierenarterien präinterventionell, am Tag nach renaler Denervation und nach einem Monat durchgeführt.

Ergebnisse: Die postinterventionellen Blutdruckmessungen (Praxisblutdruck und 24-Stundenblutdruck) wurden durchschnittlich 9,5 $\pm 3,9$ Monaten nach renaler Denervation durchgeführt. Der mittlere Praxisblutdruck sank signifikant von $177,3 \pm 20,3 / 103,8 \pm 20,4 \mathrm{mmHg}$ (systolisch/diastolisch) vor renaler Denervation auf 144,7 $\pm 14,9 / 89,5 \pm 12,1(\mathrm{p}<0,05)$ nach renaler Denerva- 
tion. Der mittlere Blutdruck in der 24-Stundenmessung nahm nicht signifikant von $155,2 \pm 20,5 / 93,7 \pm 14,5 \mathrm{mmHg}$ auf 147,9 $\pm 20,3 / 90,3 \pm 15,6$ ( $p>0,05)$ ab. Die durchschnittliche Anzahl eingenommener Antihypertensiva nahm nicht signifikant ab $(4,7$ $\pm 2,0$ vs. $4,2 \pm 1,2, p=0,18$ ). Komplikationen oder Spätfolgen wurden nicht beobachtet.

Schlussfolgerung: Durch die renale Denervation kommt es nicht zu einer signifikanten Reduktion der prognostisch wichtigen 24 Stundenblutdruckwerte. Diese Ergebnisse deuten auf einen eingeschränkten Nutzen der renalen Denervation bei therapierefraktärer Hypertonie hin.

\section{Introduction}

$\nabla$

Arterial hypertension is one of the greatest and most serious challenges facing the healthcare system worldwide [1]. It is estimated that approximately one billion people are affected by the disease [2], with 30 million living in Germany alone [3]. Left untreated, arterial hypertension increases the risk for serious cardiovascular events such as stroke, heart attack or heart failure [4]. While optimal drug therapy is available, hypertension is drug-resistant in approximately 5 to $10 \%$ of patients [5]. Hypertension is classified as drug-resistant if triple antihypertensive therapy at maximal or maximally tolerated dosage (including at least one diuretic) is unable to elicit consistent blood pressure values of $<140 \mathrm{mmHg}$ systolic and $<90 \mathrm{mmHg}$ diastolic [6]. Among other factors, a hyperactive sympathetic nervous system plays an important role in the development of hypertension [7]. While earlier therapy attempts using surgical sympathectomy in the middle of the 20th century already let to a significant reduction in blood pressure, the side effects were considerable [8]. The blood pressure reduction that was achieved with this surgical procedure was sustained over the entire observation period, which lasted up to 13 years [9]. Since 2009 a new, catheter-based, percutaneous transluminal approach has allowed minimally invasive, selective ablation of the sympathetic nerve fibers of the renal arteries [10]. This procedure is available as an additional therapy option, particularly to patients whose blood pressure could not be sufficiently lowered despite intensive drug therapy. In several studies a decrease in blood pressure following renal denervation in patients with drug-resistant hypertension could be observed [11, 12]. The observations are based primarily on one-time blood pressure measurements performed at doctor's office or a hypertension clinic ("office-based"). This article examines the effect of renal denervation on the average 24-hour ambulatory blood pressure monitoring and office-based blood pressure measurement in a highly selective patient cohort with drug-resistant hypertension. To detect later damage, pre- and post-interventional MRI examinations of the renal arteries were performed.

\section{Material and methods}

$\nabla$

\section{Patient cohort}

The study was approved by the relevant ethics committee. The inclusion criterion was having systolic blood pressure exceeding $160 \mathrm{mmHg}$ as measured at a medical office with the patient having been on antihypertensive therapy consisting of at least 3 drugs (one being a diuretic). In addition, none of the patients exhibited any sufficient decrease in blood pressure even under treatment with spironolactone. Secondary types of hypertension (e.g. renal or endocrine hypertension) were excluded prior to performing renal denervation. Pre- and post-interventional blood pressure measurements were taken as part of outpatient care. Each patient underwent 24-hour ambulatory blood pressure monitoring prior to and following renal denervation. Persons performing the blood pressure measurements were not blinded with regard to the intervention. Post-interventional office-based blood pressure measurements and 24hour ambulatory blood pressure monitoring were to be performed after 9 months.

\section{Renal denervation}

Renal denervation was performed according to the usual technique. After a femoral access (6F-sheath) was created, a flush angiography of the aorta was performed using DSA (digital subtraction angiography) (contrast agent: Solu$\operatorname{trast}^{\circledR} 300$, Bracco, Italy). The split renal denervation was then performed guided by repetitive DSA checks using an ablation catheter (Symplicity ${ }^{\mathrm{TM}}$, Medtronic, USA), which was introduced into the ostium of the renal artery with the aid of a guide catheter corresponding to the routing of the particular renal artery. Ablation points were arranged in a helical pattern and spaced approximately $5 \mathrm{~mm}$ all the way to the ostium of the renal artery. During the entire intervention, each patient was monitored and administered a sedative analgesic by an anesthesiologist. Following renal denervation, patients were administered heparin intravenously for 24 hours with a target PTT of 60 seconds and were on a thrombocyte aggregation inhibitor (aspirin $100 \mathrm{mg}$ /day) for 4 weeks.

\section{MRI examinations}

Each patient underwent a MRI examination (Intera $1.5 \mathrm{~T}$, Philips Healthcare, Best, Netherlands) of the kidneys and renal arteries one day prior to and one day following renal denervation. According to the study protocol, another renal artery MRI was performed one month following renal denervation. To detect post-interventional changes in the kidneys and renal arteries, the following sequences were acquired (see $\bullet$ Table 1 for sequence parameters): balanced Steady State with Free Precision (bSSFP) coronal and axial, bSSFP with water-selective slice excitation axial, navigatortriggered T2-weighted turbo spin echo sequence with black-blood-inversion coil, multi-phase magnetic resonance imaging (T1-weighted 3D-gradient echo sequence). A weight-adjusted dose of $0.1 \mathrm{mmol}$ per kilogram of body weight ( $\mathrm{mmol} / \mathrm{kg} \mathrm{BW}$ ) of gadubotrol (Gadovist ${ }^{\circledR}$, Bayer Healthcare, Germany) was administered as contrast agent.

\section{Statistics}

Data analysis was performed using SPSS Statistics 22.0 (IBM, Armonk, NY). A p-value of less than 0.05 was considered indicative of a significant difference. Continuous variables were tested for normal distribution. Patient characteristics are represented according to absolute frequency for categorical variables and according to mean value ( \pm standard error) for parametrically distributed variables. A sys- 
Table 1 Sequence parameters of the MRI examination protocol. The following sequence parameters were acquired: balanced Steady State with Free Precision (bSSFP) coronal and axial, bSSFP with water-selective slice excitation axial, navigator-triggered T2-weighted turbo spin echo sequence with black-blood-inversion coil, multi-phase magnetic resonance imaging (T1-weighted 3D-gradient echo sequence).

\begin{tabular}{|c|c|c|c|c|c|}
\hline & bSSFP coronal & bSSFP axial & bSSFP axial & black-blood T2 TSE & T1 - 3D-GRE \\
\hline field of view [mm] & $400 \times 340$ & $400 \times 340$ & $300 \times 105$ & $370 \times 290$ & $450 \times 400$ \\
\hline TR [ms] & 2.5 & 2.4 & 6.6 & 2000 & 2.9 \\
\hline TE [ms] & 1.26 & 1.2 & 3.3 & 28 & 0.94 \\
\hline flip angle $\left[{ }^{\circ}\right]$ & 65 & 65 & 75 & 90 & 25 \\
\hline \multicolumn{6}{|l|}{ voxel size [mm] } \\
\hline acquired & $1.92 \times 1.56 \times 6$ & $1.92 \times 1.56 \times 8$ & $1.25 \times 1.25 \times 3$ & $1.5 \times 1.65 \times 3$ & $1.17 \times 1.68 \times 2.98$ \\
\hline reconstructed & $1.39 \times 1.39 \times 6$ & $1.39 \times 1.39 \times 8$ & $0.63 \times 0.63 \times 1.5$ & $0.9 \times 0.9 \times 3$ & $0.88 \times 0.88 \times 1.49$ \\
\hline parallel imaging (SENSE) & no & no & no & yes (SENSE factor 1.5) & yes (SENSE factor 4) \\
\hline fat suppression & - & - & water-selective excitation & SPIR & - \\
\hline sequence duration[mm:ss] & $00: 19$ & $00: 36$ & $00: 19$ & 04:48 & $00: 47$ \\
\hline
\end{tabular}
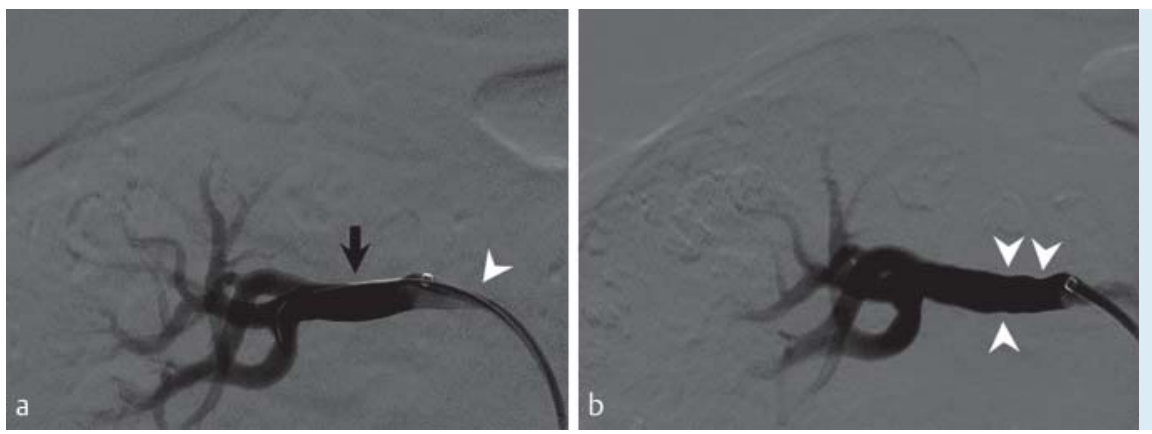

Fig. 1 a Digital subtraction angiography (DSA) of the right renal artery prior to renal denervation. A $6 \mathrm{~F}$ guide catheter (white arrow) was introduced using a Terumo guide wire (black arrow). b After renal denervation. Wall edema (white arrow) of the renal artery resulting from thermal ablation is clearly visible.

tematic differentiation of two empirical group medians was performed for variables with normal distribution using the t-test for paired random samples and for variables without normal distribution using the Wilcoxon test.

\section{Results \\ $\nabla$}

A total of 17 patients (75\% (13/17) men, 24\% (4/17) women) were prospectively included and underwent renal denervation between August 2011 and March 2013. The mean age at the time of renal denervation was $54.9 \pm 10.6$ years ( $\bullet$ Table 2 ).

For 16 of the 17 patients (94\%) ablation was performed on both renal arteries. In the case of one patient $(1 / 17(6 \%))$ renal denervation was performed on the left side only, since the right kidney had been removed 20 years prior due to pyelonephritis and nephrolithiasis.

An average of $5.8 \pm 2.1$ ablation points were placed in the right artery, while the figure for the left artery was $4.8 \pm 1.4$ $(\mathrm{p}=0.09)$. The mean drop in impedance was $16.2 \pm 3.4 \Omega$ for the right side and $14.8 \pm 3.0 \Omega$ for the left side $(\mathrm{p}=0.24)$. On average $86.5 \pm 51.9 \mathrm{ml}$ of contrast agent was consumed.

No clinical or technical complications occurred during renal denervation. DSA performed immediately following renal artery ablation detected edema of the renal artery walls in 9 of 17 (53\%). This edema was still present in the final DSA performed at the end of the intervention in 8 of 17 (44\%) patients ( $\bullet$ Fig. 1). Post-interventional MRI showed persistent edema of the renal artery wall one day following intervention in 2 of 17 patients (12\%). Follow-up MRIs performed one month following intervention yielded unremarkable findings with regard to both organ damage
Table 2 Baseline parameters for the patient cohort. Data are presented as median \pm standard deviation. Nominally scaled variable are indicated in terms of absolute frequency.

\begin{tabular}{|l|l|}
\hline parameter & value \\
\hline age [years] & $54.9 \pm 10.6$ \\
\hline males & $13 / 17(76 \%)$ \\
\hline females & $4 / 17(24 \%)$ \\
\hline body mass index $\left[\mathrm{kg} / \mathrm{m}^{2}\right]$ & $28.6 \pm 4.9$ \\
\hline creatinine $[\mathrm{mg} / \mathrm{dl}]$ & $1.28 \pm 1.10$ \\
\hline eGFR $\left[\mathrm{ml} / \mathrm{min} / 1.73 \mathrm{~m}^{2}\right]$ & $73.8 \pm 41.4$ \\
\hline
\end{tabular}

eGFR = estimated glomerular filtration rate

in general and the renal arteries in particular for all patients (17/17, 100\%).

Blood pressure measurements (office-based and 24-hour ambulatory blood pressure measurement) were repeated on average $9.5 \pm 3.9$ months (median 9.7 months) following renal denervation as part of outpatient follow-up care. The 24-hour ambulatory blood pressure monitoring showed no significant drop in systolic and diastolic blood pressure following renal denervation compared to the measurements prior to renal denervation (systolic from 155.2 $\pm 20.5 \mathrm{mmHg}$ to $147.9 \pm 20.3 \mathrm{mmHg}$ and diastolic from 93.7 $\pm 14.5 \mathrm{mmHg}$ to $90.3 \pm 15.6 \mathrm{mmHg} ; \mathrm{p}=0.58$ and $\mathrm{p}=0.88$, see - Fig. 2).

In contrast, office-based blood pressure measurements taken during follow-up care examinations were significantly reduced compared to the measurements taken prior to renal denervation (systolic from $177.3 \pm 20.3 \mathrm{mmHg}$ to 144.7 


\begin{tabular}{|c|c|c|c|c|c|}
\hline \multicolumn{2}{|l|}{ parameter } & $\begin{array}{l}\text { prior to renal } \\
\text { denervation }\end{array}$ & $\begin{array}{l}\text { following renal } \\
\text { denervation }\end{array}$ & \multirow{2}{*}{$\begin{array}{c}\text { P-value } \\
0.58\end{array}$} & \multirow{7}{*}{$\begin{array}{l}\text { Table } 3 \text { Average blood pressure } \\
\text { values and number of antihyper- } \\
\text { tensive drugs taken before and } \\
\text { after renal denervation. Data are } \\
\text { presented as median } \pm \text { standard } \\
\text { deviation. }\end{array}$} \\
\hline \multirow[t]{2}{*}{ 24-hour ambulatory blood pressure } & systolic & $155.2 \pm 20.5$ & $147.9 \pm 20.3$ & & \\
\hline & diastolic & $93.7 \pm 14.5$ & $90.3 \pm 15.6$ & 0.88 & \\
\hline \multirow[t]{2}{*}{ office-based blood pressure [ $\mathrm{mmHg}$ ] } & systolic & $177.3 \pm 20.3$ & $144.7 \pm 14.9$ & $<0.01$ & \\
\hline & diastolic & $103.8 \pm 20.4$ & $89.5 \pm 12.1$ & 0.01 & \\
\hline heart rate [beats/min] & & $71.3 \pm 13.1$ & $76.9 \pm 13.7$ & 0.41 & \\
\hline antihypertensive drugs [n] & & $4.71 \pm 2.00$ & $4.18 \pm 1.2$ & 0.18 & \\
\hline
\end{tabular}

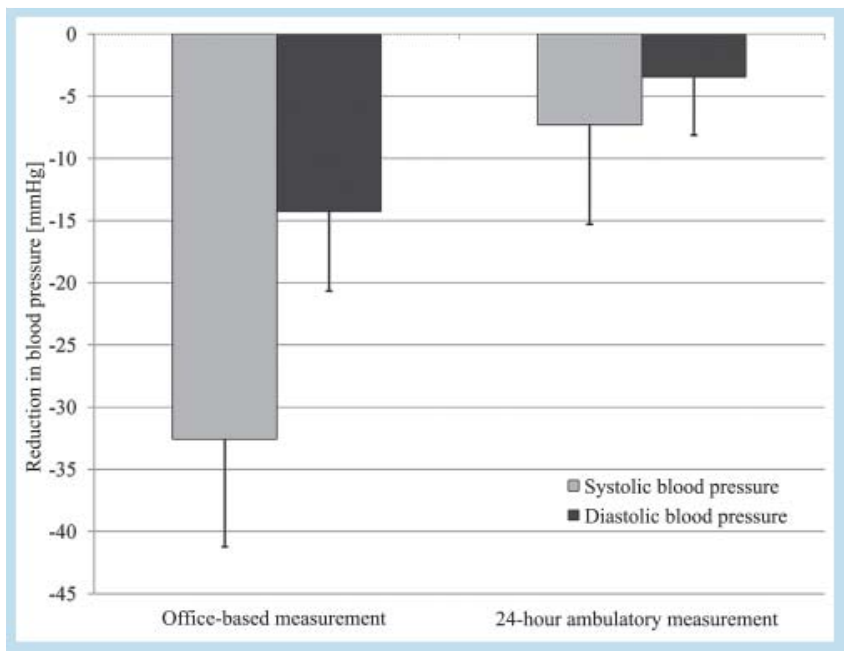

Fig. 2 Median blood pressure reduction according to office-based blood pressure measurement and according to 24-hour ambulatory blood pressure measurement following renal denervation. According to office-based measurement, systolic blood pressure decreased by $-32.6 \mathrm{mmHg}(95 \%-$ confidence interval: -24.0 to $-41.2 \mathrm{mmHg}$ ) and diastolic blood pressure decreased by $-14.3 \mathrm{mmHg}(-7.9$ to $-20.7 \mathrm{mmHg})(p<0.01$ and $p=0.01$, respectively). According to ambulatory monitoring, systolic blood pressure decreased by $-7.3 \mathrm{mmHg}(0.7$ to $-15.3 \mathrm{mmHg})$ and diastolic blood pressure decreased by $-3.5 \mathrm{mmHg}(1.2$ to $-8.2 \mathrm{mmHg})(p<0.58$ and $p=0.88$, respectively). The bar graphs represent mean blood pressure reduction (error bars $=95 \%$-confidence interval).

$\pm 14.9 \mathrm{mmHg}$ and diastolic from $103.8 \pm 20.4 \mathrm{mmHg}$ to 89.5 $\pm 12.1 \mathrm{mmHg} ; \mathrm{p}<0.01$ and $\mathrm{p}=0.01$ ).

The average number of antihypertensive drugs taken by the patients decreased insignificantly following renal denervation from $4.7 \pm 2.0$ to $4.2 \pm 1.2(\mathrm{p}=0.18,0$ Table 3$)$.

\section{Discussion}

$\nabla$

24-hour ambulatory blood pressure values are more robust and less influencable than office measurements and constitute, when elevated, an independent risk factor for hypertension-related damage [13]. This can be attributed, for one, to the frequency of the measured values during routine daily stress, which permits better evaluation of the blood pressure profile under therapy [14]. Using 24-hour ambulatory blood pressure monitoring avoids and reveals the true nature of the pronounced fluctuations between single measurements, such as those commonly seen in the case of "white coat" hypertension [15]. Approximately 5 to $10 \%$ of patients with elevated blood pressure have what is known as drug-resistant hypertension. For drug-resistant hypertension as well, only 24 -hour monitoring has prognostic validity concerning cardiovascular morbidity and mortality, while office-based blood pressure measurements performed on these patients have no prognostic value [16]. Renal denervation has been a therapy option for patients with drug-resistant hypertension since 2009 [10], with success rates of 84 to $92 \%$ being reported $[10,17]$. In a majority of studies, however, treatment was monitored using only office-based blood pressure measurements and not the prognostically more relevant 24-hour ambulatory blood pressure monitoring.

The present study used a highly selective patient cohort (prior to intervention, all patients exhibited no reduction in blood pressure even under spironolactone therapy) to examine to what extent the results of renal denervation are a function of how blood pressure was measured. For this purpose, each patient underwent 24-hour ambulatory blood pressure monitoring as part of their outpatient follow-up care on average $9.5 \pm 3.9$ months following therapy. In addition, each patient underwent pre-interventional and post-interventional MRI of the kidneys and renal arteries to detect possible organ and vascular damage.

Following renal denervation, systolic blood pressure measured at the medical office decreased significantly in our cohort by an average of $-18.4 \%$ (systolic: $-32.6 \mathrm{mmHg}$ and diastolic: $-14.3 \mathrm{mmHg})(9.5 \pm 3.9$ months following renal denervation). This result is highly consistent with those of other, previously published studies. The non-randomized proof-of-principle Symplicity Hypertension (HTN)- 1 observed a decrease in blood pressure of $-24 /-11 \mathrm{mmHg}$ in office-based measurements after a period of 9 months [10]. The randomized, yet non-blinded Symplicity HTN-2 even reported a reduction in office-based blood pressure of -32 / $-12 \mathrm{mmHg}$ in the denervation group 6 months following renal denervation [17].

Interestingly, 24-hour ambulatory blood pressure monitoring during the same period showed only a $4.7 \%$ drop in our cohort's systolic blood pressure during the same period (systolic $-7.3 \mathrm{mmHg}$ and diastolic $-3.5 \mathrm{mmHg}$ ), which does not constitute a statistically significant reduction in blood pressure.

A meta-analysis conducted by Howard et al. [18] examined this discrepancy between blood pressure reduction according to office-based measurement and 24-hour monitoring in both pharmacological studies and renal denervation studies. In pharmacological studies, the reduction in blood pressure according to office measurements and according to 24-hour ambulatory monitoring became more similar as blinding and randomization increased (so-called regression-to-the-mean effect). In fully blinded and randomized studies the reduction in office-based blood pressure is thus 
identical to the reduction in 24-hour ambulatory blood pressure. If these results are transferred to the non-randomized/non-controlled denervation studies [10,17], one could thus expect a blood pressure reduction of approximately $13 \mathrm{mmHg}$ in a randomized and controlled denervation study [18].

This is highly consistent with the results of a subgroup analysis of the Symplicity HTN-2 involving 20 patients who also underwent subsequent 24-hour ambulatory blood pressure monitoring. In this example, blood pressure reduction according to 24-hour ambulatory monitoring was clearly lower than that according to office-based measurement (reduction in blood pressure after 6 months: $-11 /-7 \mathrm{mmHg}$ ) [17]. The recently published results of the first randomized and blinded renal denervation study (Symplicity HTN-3) warrant the reevaluation of renal denervation as a therapy option [19]. This study did not achieve its primary and secondary effectivity endpoints (reduction of systolic blood pressure by more than $5 \mathrm{mmHg}$ than that of the control group according to office measurement and 24-hour monitoring, respectively.) However, the reduction in systolic blood pressure in the renal denervation group was only $2.4 \mathrm{mmHg}$ greater than that of the control group after 6 months (according to office-based measurements). The difference was even smaller for 24-hour monitoring (2.0 $\mathrm{mmHg}$ ).

The doubts surrounding the superiority of renal denervation over optimal drug therapy are also supported by a current study in which a new round of adjusted drug therapy was compared with blood pressure reduction following renal denervation in patients with drug-resistant hypertension [20]. In this cited study, the systolic office blood pressure decreased in the therapy-adjusted group after 6 months by $160 \pm 14 \mathrm{mmHg}$ to $132 \pm 10 \mathrm{mmHg}(\mathrm{P}<0.01)$, while only by $156 \pm 13 \mathrm{mmHg}$ to $148 \pm 7 \mathrm{mmHg}(P=0.42)$ in the renal denervation group. The study was prematurely discontinued due to ethical concerns [20].

These current results and our own data show that using renal denervation must still be regarded as an experimental procedure and that no clinical benefits have been clearly demonstrated to date.

A possible explanation for the better blood pressure reduction results in the aforementioned studies $[10,12,17]$ may be, in addition to the regression-to-the-mean-effect, the socalled detection bias or the absence of a control group. Because the study presented in this article was likewise not blinded, the discrepancy between blood pressure reduction according to office-based measurement and 24-hour ambulatory monitoring is primarily caused by a detection bias, $\mathrm{i}$. e., by an incorrectly positive evaluation of office blood pressure on the part of the examiner, and by the regression-tothe-mean-effect. Future studies must therefore define 24hour blood pressure monitoring as primary study endpoint. Renal denervation is a safe and easy-to-perform procedure. It was performed on our entire patient cohort without any complications occurring in the course of the procedure. The post-interventional MRI follow-up examinations performed on the day after renal denervation revealed intramural, ablation-induced edema of the renal artery wall in only two patients. Follow-up care examinations yielded unremarkable findings in this regard for all patients $(17 / 17$, $100 \%$ ). Overall, our results are consistent with the likewise very low rate of complications reported in previously published studies $[10,11,17,19]$. However, it should be noted that de novo renal artery stenosis following renal denervation has been reported [21, 22].

The small patient cohort is a limitation of the present study. On the other hand, the study was composed of a highly selective group of "truly" drug-resistant hypertension patients for whom even spironolactone therapy did not bring about sufficient reduction in blood pressure. Another limitation is the absence of a control group. This allowed only interindividual comparison of the post-interventional measurements. Because changes to antihypertensive medication were not systematically recorded, it is not possible to make any statements on the impacts therapy modification (e. g. in the case of switching a group of active substances). The present study demonstrated no significant reduction in 24-hour ambulatory blood pressure values following renal denervation. Renal denervation should therefore not be offered as a routine procedure at this point, and its use should currently be limited to clinical studies.

\section{Clinical Relevance of the Study}

- 24-hour ambulatory blood pressure monitoring performed as a follow-up to renal denervation revealed no significant reduction in blood pressure.

- No complications were observed during the procedure and no later damage to the kidneys or renal arteries was detected in the long-term follow-up MRI examinations.

- Currently, renal denervation should not be performed outside clinical studies.

\section{References}

1 Ezzati M, Lopez AD, Rodgers A et al. Selected major risk factors and global and regional burden of disease. Lancet 2002; 360: 1347-1360

2 Kearney PM, Whelton M, Reynolds $K$ et al. Global burden of hypertension: analysis of worldwide data. Lancet 2005; 365: 217-223

3 Nahle $C P$, Schild $H$, Wilhelm $K$. Renal denervation: ready for prime time? Dtsch Med Wochenschr 2013; 138: 2212-2218

4 Bobrie G, Chatellier G, Genes $N$ et al. Cardiovascular prognosis of "masked hypertension" detected by blood pressure self-measurement in elderly treated hypertensive patients. JAMA 2004; 291: 1342 - 1349

5 Calhoun DA, Jones $D$, Textor $S$ et al. Resistant hypertension: diagnosis, evaluation, and treatment. A scientific statement from the American Heart Association Professional Education Committee of the Council for High Blood Pressure Research. Hypertension 2008; 51: 1403 - 1419

6 Mancia G, Fagard R, Narkiewicz Ket al. 2013 ESH/ESC guidelines for the management of arterial hypertension: the Task Force for the Management of Arterial Hypertension of the European Society of Hypertension (ESH) and of the European Society of Cardiology (ESC). Eur Heart J 2013; 34: 2159-2219

7 Esler M, Ferrier C, Lambert $G$ et al. Biochemical evidence of sympathetic hyperactivity in human hypertension. Hypertension 1991; 17: III29III35

8 Smithwick RH, Thompson JE. Splanchnicectomy for essential hypertension; results in 1266 cases. J Am Med Assoc 1953; 152: 1501 - 1504

9 Grimson KS, Orgain ES, Anderson B et al. Total thoracic and partial to total lumbar sympathectomy, splanchnicectomy and celiac ganglionectomy for hypertension. Ann Surg 1953; 138: $532-547$

10 Krum H, Schlaich M, Whitbourn $R$ et al. Catheter-based renal sympathetic denervation for resistant hypertension: a multicentre safety and proof-of-principle cohort study. Lancet 2009; 373: 1275-1281 
11 Krum H, Schlaich MP, Sobotka PA et al. Percutaneous renal denervation in patients with treatment-resistant hypertension: final 3-year report of the Symplicity HTN-1 study. Lancet 2014; 383: 622 -629

12 Worthley SG, Tsioufis CP, Worthley MI et al. Safety and efficacy of a multi-electrode renal sympathetic denervation system in resistant hypertension: the EnligHTN I trial. Eur Heart J 2013; 34: 2132 -2140

13 Clement DL, De Buyzere ML, De Bacquer DA et al. Prognostic value of ambulatory blood-pressure recordings in patients with treated hypertension. N Engl J Med 2003; 348: 2407 - 2415

14 Schrader J, Schoel G, Buhr-Schinner H et al. Comparison of the antihypertensive efficiency of nitrendipine, metoprolol, mepindolol and enalapril using ambulatory 24-hour blood pressure monitoring. Am J Cardiol 1990; 66: 967 -972

15 Pickering TG, James GD, Boddie C et al. How common is white coat hypertension? JAMA 1988; 259: 225 - 228

16 Salles GF, Cardoso CR, Muxfeldt ES. Prognostic influence of office and ambulatory blood pressures in resistant hypertension. Arch Intern Med 2008; 168: 2340-2346
17 Esler MD, Krum H, Sobotka PA et al. Renal sympathetic denervation in patients with treatment-resistant hypertension (The Symplicity HTN2 Trial): a randomised controlled trial. Lancet 2010; 376: 1903-1909

18 Howard JP, Nowbar AN, Francis DP. Size of blood pressure reduction from renal denervation: insights from meta-analysis of antihypertensive drug trials of 4121 patients with focus on trial design: the CONVERGE report. Heart 2013; 99: 1579-1587

19 Bhatt DL, Kandzari DE, O'Neill WW et al. A Controlled Trial of Renal Denervation for Resistant Hypertension. N Engl J Med 2014; 370: 1393 1401

20 Fadl EFE, Hoffmann P, Larstorp AC et al. Adjusted drug treatment is superior to renal sympathetic denervation in patients with true treatment-resistant hypertension. Hypertension 2014; 63: 991 -999

21 Kaltenbach B, Id D, Franke JC et al. Renal artery stenosis after renal sympathetic denervation. J Am Coll Cardiol 2012; 60: 2694-2695

22 Vonend 0 , Antoch G, Rump LC et al. Secondary rise in blood pressure after renal denervation. Lancet 2012; 380: 778 